\title{
Epidemiology, clinical presentation, treatment, and follow-up of chronic mercury poisoning in China: a retrospective analysis
}

Sun Yawei ${ }^{1 \dagger}$, Long Jianhai ${ }^{2+}$, Zhao Junxiu', Peng Xiaobo ${ }^{1 *}$ and Qiu Zewu ${ }^{1 *}$ (D)

\begin{abstract}
Background: There are no reports on the incidence of chronic mercury poisoning in a large population in China. This study investigated the epidemiology, clinical manifestations, treatment, and follow-up of Chinese patients with chronic mercury poisoning.

Methods: Data for 288 mercury poisoning patients were collected at our hospital from July 2014 to September 2019, including sex, age, admission time, blood mercury content, urine mercury content, creatinine, urinary mercury/creatinine ratio, 24-h urinary protein levels, electromyography (EMG) findings, renal biopsy, and follow-up. Patient characteristics were evaluated by statistical and correlation analyses.

Results: First, mercury poisoning in China mainly occurred through occupational exposure and the inappropriate use of mercury-containing cosmetics and Chinese folk remedies (CFRs). Second, the most common symptoms were nervous system (50.3\%), kidney (16.4\%) and breathing (8.0\%). Mercury poisoning-induced Nephrotic syndrome (NS) and peripheral neuropathy are common long-term complications. The complications of occupational and cosmetics-induced mercury poisoning are consistent with international belief. However, the NS caused by CFRs is mainly membranous nephropathy and the probability of peripheral neuropathy caused by CFRs is higher than other pathogens. Third, follow-up data shows that 13 patients with EMG-confirmed neurological injury, 10 showed full recovery after $38.50 \pm 8.03$ months. Furthermore, among 18 patients with NS, 15 had normal urine protein and serum albumin levels after $22.67 \pm 10.26$ months.
\end{abstract}

Conclusions: Regulation of skin-lightening cosmetic products, safety surveillance of CFRs, and prevention and control of occupational exposure must be improved to decrease the incidence of mercury poisoning in China.

Keywords: Toxicology, Nephrology, Neurology, Epidemiology

\footnotetext{
*Correspondence: xiaobopeng911@163.com; qiuzw828@163.com

†Sun Yawei and Long Jianhai contributed equally to this work.

'Department of Chemical Poisoning Treatment, Department of Hematology,

Fifth Medical Center of Chinese PLA General Hospital, No. 8 Dong da Street,

Fengtai District, 100071 Beijing, China

Full list of author information is available at the end of the article
}

C C The Author(s). 2021 Open Access This article is licensed under a Creative Commons Attribution 4.0 International License, which permits use, sharing, adaptation, distribution and reproduction in any medium or format, as long as you give appropriate credit to the original author(s) and the source, provide a link to the Creative Commons licence, and indicate if changes were made. The images or other third party material in this article are included in the article's Creative Commons licence, unless indicated otherwise in a credit line to the material. If material is not included in the article's Creative Commons licence and your intended use is not permitted by statutory regulation or exceeds the permitted use, you will need to obtain permission directly from the copyright holder. To view a copy of this licence, visit http://creativecommons.org/licenses/by/4.0/ The Creative Commons Public Domain Dedication waiver (http://creativecommons.org/publicdomain/zero/1.0/) applies to the data made available in this article, unless otherwise stated in a credit line to the data. 


\section{Background}

Mercury ( $\mathrm{Hg}$ ) poisoning has been a major public health in the world. People showed different clinical manifestations when exposed in different ways to different forms of mercury, such as $\mathrm{Hg}$ vapour $\left(\mathrm{Hg}^{0}\right)$ target damage the brain and kidney, inorganic $\mathrm{Hg}$ (IHg) target damage the kidney, and organic $\mathrm{Hg}$ (OHg, assumed to be methylmercury; MeHg) target damage the brain [1]. The levels of urinary $\mathrm{Hg}$ and $\mathrm{MeHg}$ in the majority of the general public in China were below the reference value set by the Chinese health authority, except for a few mining areas, due to abundant food resources and low concentration of methylmercury in inland cultured fish. [2, 3]. Epidemiological data show that mercury poisoning mainly results from occupational contact with mercury, abuse of mercury-containing compounds, or the use of skin-lightening cosmetic products [4-6]. Mercury poisoning is caused by inhalating $\mathrm{Hg}^{0}$ or eating foods polluted by $\mathrm{IHg}$ in a variety of industrial settings, including the chlor-alkali industry $\left(\mathrm{Hg}^{0}\right)$, thermometer $\left(\mathrm{Hg}^{0}\right)$ and fluorescent lamp manufacturing facilities $\left(\mathrm{Hg}^{0}\right)$, as well as chemical processing $\left(\mathrm{Hg}^{0}, \mathrm{IHg}\right)$, and dental practices $\left(\mathrm{Hg}^{0}\right)$ [5, 7]. Mercury poisoning absorbs IHg via the trans-epidermal and trans-appendageal routes, such as mercurous chloride, mercurous oxide, mercuric chloride and ammoniated mercury [8], following the use of skinlightening creams has been reported in Africa, Europe, the United States, Mexico, Australia, and Hong Kong [8]. Analysis of 19 creams from China, Thailand, and Vietnam showed that they contained mercury at concentrations ranging from 0.01 to 12 , $590 \mathrm{mg} \cdot \mathrm{kg}^{-1}$ [9]. Mercury-containing compounds have been used for centuries for commercial and medical purposes and are a common constituent of traditional Chinese medicines (TCMs), such as HgS [10]. Unlike TCMs, which are formally approved medical treatments and have reasonably safe levels of bioaccessible $\mathrm{Hg}$ [11], Chinese folk remedies (CFRs) induce mercury poisoning via the inhale $\mathrm{Hg}^{\mathrm{O}}$ or oral $\mathrm{HgS}$ routes which involve an informal use of TCMs, rely mostly on experience rather than on formal teachings, and have not been approved by the government [12]. Although incidents of mercury poisoning in China have been occasionally reported domestically and abroad $[13,14]$, there have been no clinical studies involving a large sample size to date. In the present study, we carried out a retrospective analysis of the clinical manifestations, treatment, and follow-up of Chinese patients with mercury poisoning. Our findings provide important information for clinicians and health authorities on the pathogeny of mercury poisoning in China.

\section{Methods}

\section{Patients}

This study was a single-center, retrospective analysis conducted at a 52-bed poisoning treatment center in Fengtai District, Beijing, China. Poisoning patients were mainly admitted from northern, central, and eastern China. The STROBE (strengthening the Reporting of Observational studies in Epidemiology) criteria were followed. In this retrospective study, we analyzed the data for patients treated for mercury poisoning between July 2014 and September 2019 at The Poisoning Treatment Department of The Fifth Medical Center of the PLA General Hospital in China. In total, 288 cases were screened according to the flowchart (Fig. 1). The inclusion criteria were as follows: (1) mercury was detected in the blood and urine, and the urinary mercury/creatinine (UMC) ratio was larger than $20 \mu \mathrm{mol} / \mathrm{mol}$, which was the chronic $\mathrm{Hg}$ exposure limit $(35.0 \mu \mathrm{g} / \mathrm{g}$ creatinine $\approx 20$ $\mu \mathrm{mol} / \mathrm{mol}$ ) set by the Chinese Occupational Health Standard (WS/T 265-2006) [2]; and (2) at least one of the following symptoms was present: neurasthenia syndrome (dizziness, fatigue, insomnia, dreaming, forgetfulness, and inattention), tremor, limb or trunk pain, oral gingivitis, proteinuria, etc. The exclusion criteria were as follows: (1) diseases that may cause nephrotic syndrome (NS) or peripheral nerve injury, such as systemic lupus erythematosus, hepatitis B or $\mathrm{C}$, or diabetes, as well as trauma-, drug-, or arsenicinduced peripheral nerve injury; and (2) mercury poisoning within $24 \mathrm{~h}$ or only once. All study participants provided informed consent, and this retrospective study design was approved by the appropriate ethics review board of our hospital.

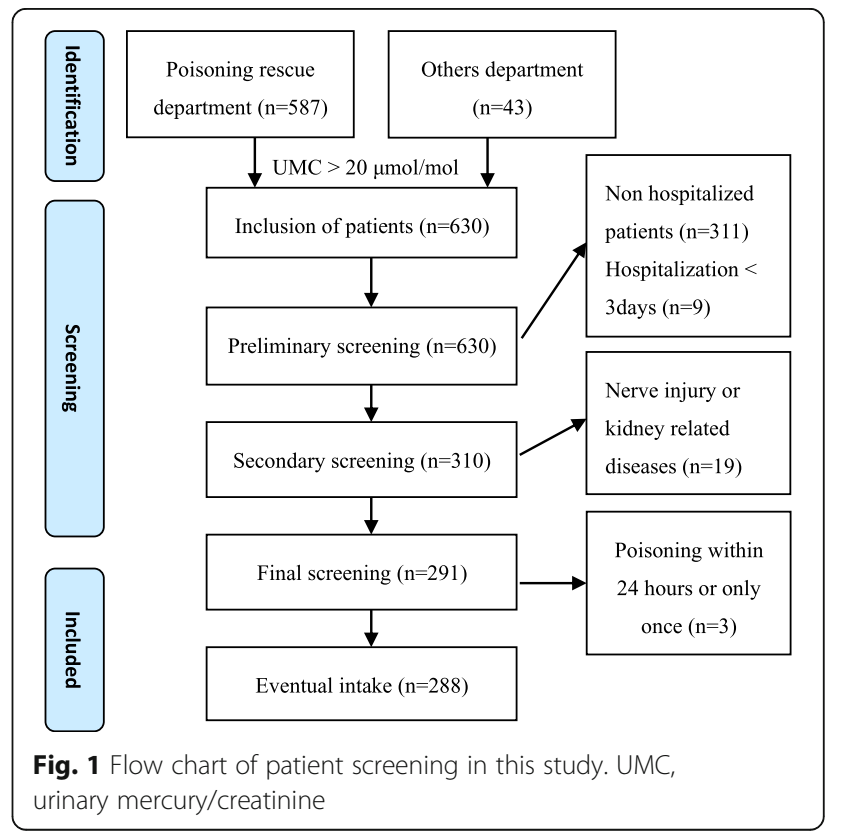




\section{Data collection}

Patient data included baseline characteristics (age, sex, and time of admission); test results, including the creatinine level, blood mercury content, urine mercury content [high urine mercury (HUM): UMC > the biological exposure limit of $20 \mu \mathrm{mol} / \mathrm{mol}$ creatinine], and 24-h urinary protein level (reference value $<150 \mathrm{mg} / 24 \mathrm{~h}$ ), collected 1 day after admission; and electromyography (EMG) findings, which were based on the first EMG after admission; and renal biopsy which was performed at an external hospital, and no repeated examination was carried out after admission and during follow-up visits. Mercury concentrations were measured by inductively coupled plasma mass spectrometry using an Agilent 7500ce instrument (Agilent, Santa Clara, CA, USA).

\section{Statistical analysis}

Statistical analyses were performed using the STATA v.13.0 software. Categorical data are reported as numbers and differences were evaluated using the $x^{2}$ test. Continuous variables were assessed for departure from normality using the Shapiro-Wilk $W$-test with $\alpha=0.10$. Normally distributed parametric data are presented as the mean \pm standard deviation. Parametric data with skewed distributions are presented as the median \pm interquartile range (IQR). Differences between groups were compared using the Student's $t$-test and Kruskal-Wallis test for normally and non-normally distributed variables, respectively. Correlation analysis between multi-factor and peripheral neuropathy: For the categorical data, we did chi-square test. For the continuous variables, we did logistic analysis. Two-sided $p$ values are presented, which were considered statistically significant at $p<0.05$.

\section{Results}

\section{Baseline characteristics}

Between 2014 and 2019, 288 patients (189 females and 99 males) were hospitalized for mercury poisoning. The mean age was $38.1 \pm 12.2$ years (range: $3-71$ years). In 84 patients $(29.27 \%)$, the poisoning was related to cosmetics: the products were not registered in the administration for Industry and Commerce; in some cosmetic products, an excessive mercury content was detected at professional institutions; and some users presented a phenomena that deactivating the same cosmetics products for 6 to 12 months, their UMC was keep in the normal range. In 66 patients $(23 \%)$, the poisoning was occupational (forestry work, metallurgy, and machine manufacturing), and $\mathrm{HgO}$ and $\mathrm{Hg}^{2+}$ could clearly be detected at the factory. In 46 patients (16\%), the poisoning was related to CFRs; these patients took CFRs during or before the onset of symptoms, mostly for simple, chronic, and benign illnesses, including the management of psoriasis $(n=19,41.3 \%)$, venous thrombosis $(n=1)$, cervical lymphadenopathy $(n=1)$, acne removal $(n=2)$, insomnia $(n=4)$, migraine $(n=3)$, depression $(n=1)$, glioma $(n=1)$, facial paralysis $(n=2)$, allergic purpura $(n=$ $1)$, urticaria $(n=2)$, rubella $(n=1)$, pruritus of the perineum $(n=1)$, and cervical spondylopathy $(n=2)$, but also as an anodyne $(n=1)$ or for health preservation $(n=4)$. Most CFRs contain cinnabar ( $\mathrm{HgS})$, calomel ( $\mathrm{Hg}_{2} \mathrm{Cl}_{2}$ ), or other mercury-containing Chinese herbal medicines and even directly use mercury beads $\left(\mathrm{Hg}^{\mathrm{O}}\right)$ for heating inhalation. In the remaining 92 patients (32\%), the source of poisoning was unclear; however, accessory examination showed HUM, accompanied by systemic symptoms such as headache, dizziness, tremor, or obvious proteinuria $(++)$.

Comparison of patients with occupational mercury poisoning, mercury poisoning caused by cosmetics, and mercury poisoning caused by CFRs showed no obvious differences in their blood mercury content $\left(\chi^{2}=1.05\right.$, $p=0.590)$, urinary mercury content $\left(\chi^{2}=3.29, p=0.190\right)$, and UMC ratio $\left(\chi^{2}=3.86, p=0.140\right)$. The poisoning age distribution showed that most of male patients were aged between 20 and 50 and female patients were aged between 31 and 50. Occupational mercury poisoning is the highest constituent ratio in male $\left(x^{2}=3.883, p=\right.$ 0.049 ), while mercury poisoning was caused by cosmetics in female $\left(x^{2}=21.22, p<0.001\right)$. Among the patients with mercury poisoning caused by CFRs, there was no sex difference $\left(\chi^{2}=0.004, p=0.949\right)$, but there was the first constituent ratio in the male group aged larger than 50 and female group aged larger than 60 (Fig. 2).

\section{Clinical findings}

The median duration of hospitalization was 14 days (range: 3-67 days). There was no correlation between the duration of hospitalization and the source of mercury poisoning $\left(\chi^{2}=1.86, p=0.396\right)$. Table 1 shows the symptoms of the 288 patients with mercury poisoning. The most common general symptoms were neurological, nephrological, respiratory, gastrointestinal, and dermatological.

\section{Laboratory findings}

Table 2 shows the laboratory findings. There were significant differences in the blood mercury concentrations $\left(\chi^{2}=10.77, p=0.005\right)$ but no significant differences in the urine mercury content $\left(\chi^{2}=4.68, p=0.100\right)$ and UMC ratio $\left(\chi^{2}=3.32, p=0.190\right)$ between the patients with NS or peripheral nerve injury and those with noncomplication mercury poisoning. Renal biopsy was performed in 39 patients, of which 20 (51.28\%) presented with membranous nephropathy (MN), 14 (35.5\%) with minimal-change nephropathy (MCN), three (7.69\%) with mesangial proliferative glomerulonephritis (MSPG 


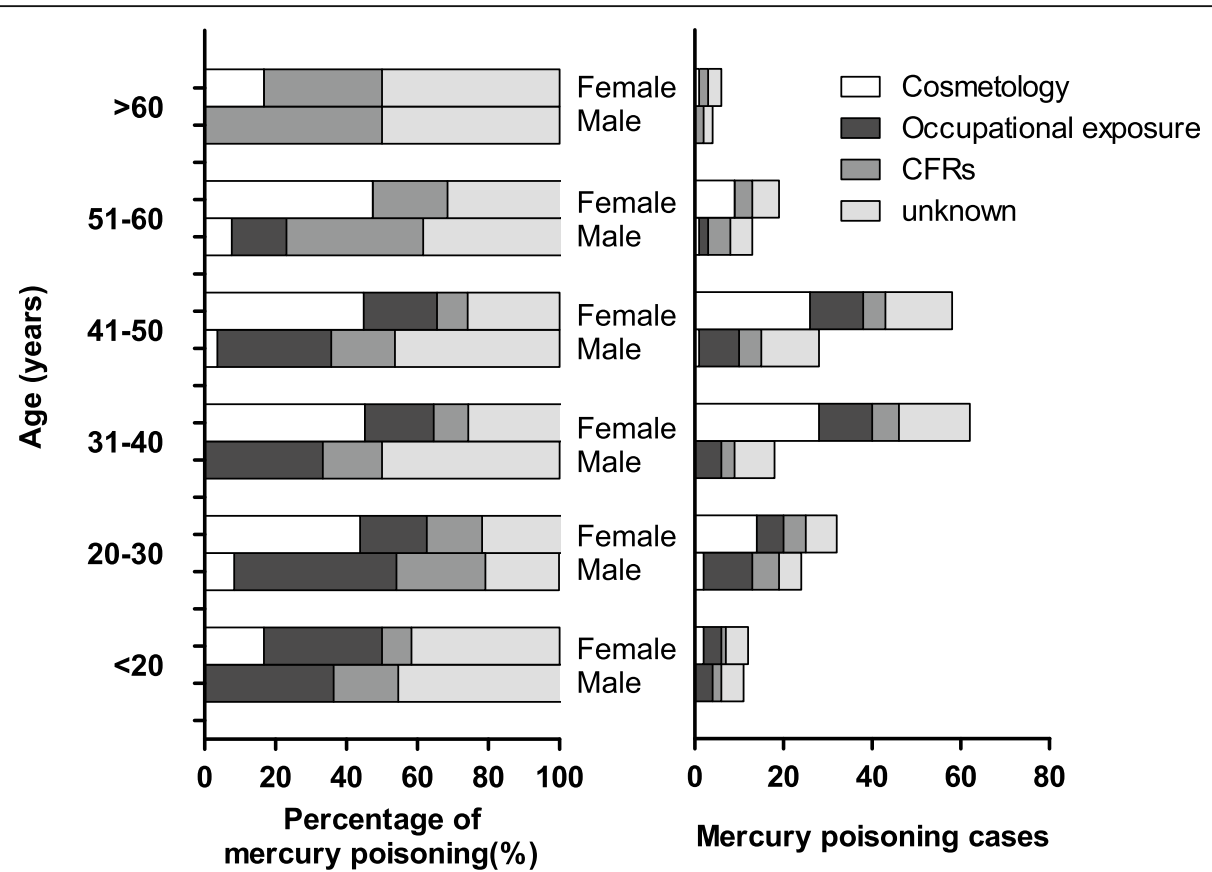

Fig. 2 Distribution of mercury poisoning patients by disease etiology, sex, and age. CFRs, Chinese folk remedies. CFRs, Chinese folk remedies

Table 1 Symptoms observed in 288 patients with mercury poisoning

\begin{tabular}{lll}
\hline Symptoms & Subgroup & Numbers (\%) \\
\hline Neurological & & $145(50.3 \%)$ \\
& Pain in extremities & $57(19.8 \%)$ \\
& Numbness in extremities & $58(20.1 \%)$ \\
& Tremor in extremities & $10(3.5 \%)$ \\
& Dizziness and headaches & $23(8.0 \%)$ \\
& Myoasthenia & $8(2.8 \%)$ \\
& Memory problems & $3(1.0 \%)$ \\
Nephrology & Insomnia & $8(2.8 \%)$ \\
& & $76(26.4 \%)$ \\
& Edema & $45(15.6 \%)$ \\
& Foamed urine & $17(5.9 \%)$ \\
& Nephrotic syndrome & $39(13.5 \%)$ \\
& Hematuria & $2(0.7 \%)$ \\
& & $23(8.0 \%)$ \\
Respiratory & Shortness of breath & $9(3.1 \%)$ \\
& Chest tightness & $22(7.6 \%)$ \\
& & $15(5.2 \%)$ \\
& Pastrointestinal & $9(3.1 \%)$ \\
& Nausea and vomiting & $6(2.1 \%)$ \\
& & $5(1.7 \%)$ \\
& & $5(1.7 \%)$ \\
\hline
\end{tabular}

$\mathrm{N})$, and two $(5.13 \%)$ with focal segmental glomerulosclerosis (FSGS). The incidences of MN and MCN were higher than those of the other types of NS $\left(\chi^{2}=24.10\right.$, $p<0.001)$. There were no differences in UMC ratios among the four types of NS $\left(X^{2}=2.12, p=0.548\right.$; Fig. 3a). MN was mainly detected in patients for whom the source of mercury poisoning was cosmetic products or improperly used CFRs $\left(\chi^{2}=8.40>\chi^{2}[0.05,3]=5.84, p<\right.$ 0.050; Fig. 3b). MCN mainly occurred in patients who used cosmetic products containing mercury $\left(x^{2}=22>X^{2}\right.$ $[0.05,3]=12.92, p<0.050$; Fig. 3b). EMG was performed in 39 patients with neuroparesthesia (Table 3). We examined the relationships between the EMG findings and age, sex, duration of hospital stay, pathogeny, blood mercury concentrations, urine mercury concentrations, creatinine, and UMC ratios and found that as the age, the probability of mercury-induced peripheral neuropathy is increased $\left(\mathrm{OR}=1.07, \mathrm{x}^{2}=3.93, p<0.001\right)$. Patients with mercury poisoning caused by improperly used CFRs were more likely to have peripheral neurogenic damage $\left(x^{2}=13.60, p=0.003\right)$.

\section{Diagnosis and treatment}

All 288 patients were diagnosed with mercury poisoning based on the clinical manifestations and UMC values and underwent symptomatic treatment, which included intramuscular injection ( $0.25 \mathrm{~g}$ twice a day) of sodium 2 , 3-dimercapto-1-propanesulfonate (DMPS) for 3 consecutive days, followed by 4 days of intermittent treatment, for mercury excretion, and detecting once UMC 
Table 2 Laboratory examination of 288 patients with mercury poisoning

\begin{tabular}{|c|c|c|c|c|c|}
\hline Laboratory examination & Subgroup & Value & & Statistic & $\mathbf{P}$ \\
\hline \multirow[t]{4}{*}{ Blood mercury content ${ }^{a}$, medain $(\mathrm{IQR}), \mu \mathrm{g} / \mathrm{L}$} & & 9.35 (4.20 to 21.00$)$ & | Vs || Vs ||| & 10.77 & 0.005 \\
\hline & Non-complication, I & 8.20 (3.60 to 20.60$)$ & III Vs I| & 5.26 & 0.022 \\
\hline & Nephrotic syndrome ${ }^{d}, \|$ & 16.70 (7.80 to 37.80$)$ & || Vs I & 10.47 & 0.001 \\
\hline & Peripheral nerve injury ${ }^{d}$, II & 10.20 (5.20 to 17.20$)$ & ||I Vs I & 0.35 & 0.554 \\
\hline \multirow[t]{4}{*}{ Urine mercury content ${ }^{\mathrm{a}}$, medain(IQR), $\mathrm{\mu g} / \mathrm{L}$} & & 13.50 (5.10 to 29.60$)$ & | Vs || Vs ||| & 4.68 & 0.096 \\
\hline & Non-complication, I & $13.25(4.9$ to 29.1$)$ & III Vs I| & 4.18 & 0.041 \\
\hline & Nephrotic syndrome, II & 20.9 (8.3 to 37.8$)$ & $\|$ Vs I & 3.17 & 0.075 \\
\hline & Peripheral nerve injury, III & 9.5 (4.9 to 20$)$ & |II Vs | & 0.93 & 0.335 \\
\hline Creatinine,medain $(\mathrm{IQR}), \mu \mathrm{mol} / \mathrm{L}$ & & 56 (49 to 66$)$ & & & \\
\hline \multirow[t]{4}{*}{$\mathrm{UMC}^{\mathrm{a}}$, medain $(\mathrm{QQR}), \mu \mathrm{mol} / \mathrm{molb}$} & & 128.57 (40.35 to 277.22$)$ & | Vs || Vs ||| & 3.32 & 0.19 \\
\hline & Non-complication, I & 125.18 (37.68 to 269.84) & III Vs I| & 2.63 & 0.105 \\
\hline & Nephrotic syndrome, II & 205.38 (70.34 to 411.36) & $\| V_{s} \mid$ & 2.89 & 0.089 \\
\hline & Peripheral nerve injury, III & 221.95 (93.51 to 472.06) & |II Vs I & 0.11 & 0.746 \\
\hline 24-h urinary protein, median (IQR), g/24 h & & $0.42(0.26$ to 2.75$)$ & & & \\
\hline \multirow[t]{5}{*}{ Renal biopsy ${ }^{b}, n(\%)^{c}$} & & $39(13.5 \%)$ & & 24.10 & $<0.001$ \\
\hline & MN & $20(51.3 \%)$ & & & \\
\hline & $\mathrm{MCN}$ & $14(35.9 \%)$ & & & \\
\hline & MSPGN & $3(7.7 \%)$ & & & \\
\hline & FSGS & $2(5.1 \%)$ & & & \\
\hline \multirow[t]{4}{*}{$E M G^{b}, n(\%)$} & & $39(13.5 \%)$ & & 6.79 & 0.036 \\
\hline & Neuropathy & 33 & & & \\
\hline & Myopathy & 1 & & & \\
\hline & FW & 5 & & & \\
\hline
\end{tabular}

EMG electromyography, FSGS focal segmental glomerulosclerosis, FW F-wave, IQR interquartile range, MCN minimal-change nephropathy, MN membranous nephropathy, MSPGN mesangial proliferative glomerulonephritis, UMC urinary mercury/creatinine

${ }^{a}$ One-way analysis of variance by ranks (Kruskal-Wallis Test)

${ }^{b} x^{2}$ test

'Subgroup's constituent ratio

dNephrotic syndrome's diagnosis was established by renal biopsy and nerve injury's diagnosis was established by EMG

ratio after twice courses. Combining some symptomatic treatments such as administration of calcium carbonate (3 g twice a day orally), Shenkang injection $(100 \mathrm{~mL}$ once a day as an intravenous infusion), painkillers (10 mg of tramadol once or twice a day or $5 \mathrm{mg}$ of oxycodone), glucocorticoids (prednisone), and neurotrophic drugs $(20 \mu \mathrm{g} /$ day mouse nerve growth factor for injection, $1.5 \mathrm{mg} /$ day cobamamide, or $0.5 \mathrm{~g} /$ day citicoline sodium). For treatment of the 39 patients with NS, prednisone was administered at $1 \mathrm{mg} / \mathrm{kg} /$ day for 8 weeks, followed by a progressive decrease by $5 \mathrm{mg}$ ( 1 tablet) every 2 weeks, based on the 24-h urinary protein level. Prednisone administration usually resulted in a rapid (within 2-3 days) improvement of the patient's clinical status, with a decrease in fever. In the cases with nerve injury, a neurotrophic factor was administered to reduce the myelin swelling and prevent the nerve fiber degeneration.

\section{Follow-up}

Some patients were from underdeveloped regions, of which 280/288 patients were rechecked within 6 months to 1 year after discharge, and their UMC values were found to be in the normal range (outpatient query system). Unfortunately, after the first re-examination, most patients did not continue to seek treatment and were followed up via telephone calls in September 2020. Only 249 patients were successfully evaluated in the second follow-up, with the median follow-up time of 46 months (IQR: 30-54 months). Among the patients without complications, 218 reported no abnormal symptoms. For patients with NS diagnosed by biopsy, the last 24-h urine protein report was sent via WeChat or a multimedia message as an image to the mobile phone. Of the $18 \mathrm{pa}-$ tients with NS, who successfully completed follow-up visits, 10 patients were diagnosed with $\mathrm{MN}$, six patients with $\mathrm{MCN}$, and one each patient with FSGS 

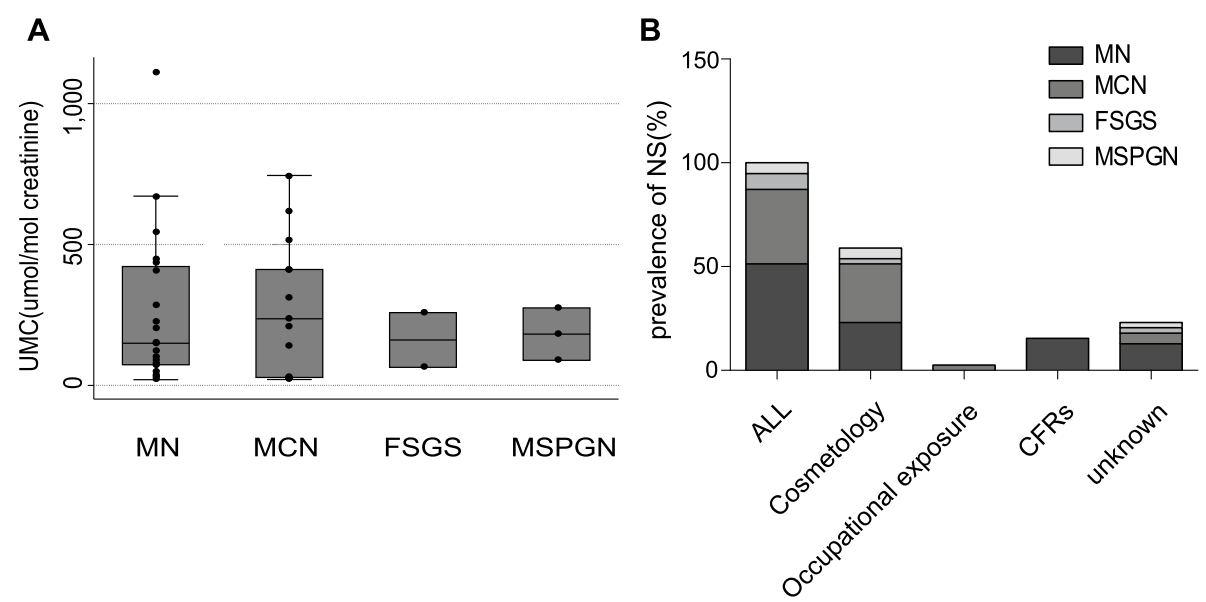

Fig. 3 Urinary mercury/creatinine ratio and constituent ratio in 39 cases of mercury poisoning with NS. a Distribution of the UMC ratio in accordance with the type of NS. b Constituent ratio of different types of NS according to etiology. CFRs, Chinese folk remedies; FSGS, focal segmental glomerulosclerosis; MCN, minimal-change nephropathy; MN, membranous nephropathy; MSPGN, mesangial proliferative glomerulonephritis; NS, nephrotic syndrome; UMC, urinary mercury/creatinine

and MSPGN. Two patients with MN and one with MCN did not undergo urinary protein re-examination because of the lack of symptoms. For the other NS patients, their urinary protein and serum albumin levels recovered to normal ranges after $22.67 \pm 10.26$ months. None of the patients underwent a second renal biopsy. For patients with nerve damage, diagnosed by EMG, their symptoms were carefully examined through phone call inquiries, and their latest rechecked EMG reports were sent via WeChat as an image. Of the 13 patients with EMG-confirmed neurological injury, who were followed up, 10 patients showed full recovery after $38.50 \pm 8.03$ months (EMGs of eight patients confirmed recovery, and two patients confirmed that they had no discomfort), two showed improvements relative to their previous state, and one showed no change.

Table 3 Correlation analysis between multi-factor and peripheral neuropathy

\begin{tabular}{llll}
\hline Peripheral neuropathy & OR & Statistic & $\mathbf{p}$ \\
\hline Age & 1.07 & 3.93 & $<0.001$ \\
Sex & & 0.05 & 0.83 \\
Pathogeny & 13.6 & 0.003 \\
Urine mercury & 1.18 & 0.239 \\
Blood mercury & 0.24 & 0.812 \\
Urine protein & -0.12 & 0.904 \\
Creatinine & -0.75 & 0.452 \\
UMC ratio & 1.16 & 0.247 \\
Hospitalization & -0.58 & 0.56 \\
\hline
\end{tabular}

EMG electromyography, OR odds ratio, UMC urinary mercury/creatinine

\section{Discussion}

We report the epidemiology, treatment, and prognosis of patients admitted with mercury poisoning to a hospital in China. We mainly clarified the following three aspects: (1) different mercury poisoning-induced pathogenies show sex and age difference; (2) there was a certain relationship between different pathogenies and mercury poisoning-induced complications; and (3) a clear diagnosis and timely treatment of mercury poisoning are necessary.

The gender and age distribution of occupational mercury poisoning patients are as described above, but most of the occupational exposure are hospitalized in occupational hospitals throughout the country, so the distribution is worth further discussion. Meanwhile, we report that mercury-containing cosmetic products are the main cause of mercury poisoning in females. Mercury is absorbed by the skin [8] and can cause many complications such as nephrotic syndrome and peripheral nerve injury. Unfortunately, skin-lightening creams containing inorganic mercury are widely used by dark-skinned people to achieve a lighter skin tone $[9,15]$. In China, TCM can be confused with CFRs. Most patients from this study improperly used CFRs for simple, chronic, and benign illnesses [12], the situation of this study are consistent with above. Meanwhile, this study indicates that the CFRs-induced mercury poisoning is the highest constituent ratio in elderly patients ( $>50$ years old in male and $>60$ years old in female). Before the $1970 \mathrm{~s}$, people had a low level of education and maintained a high trust to CFRs [16].

Long-term mercury exposure causes damage to several organ systems, including the nervous, urinary, digestive, 
and respiratory systems [17]. Neurological manifestations of inorganic mercury intoxication include weakness, numbness, paresthesia, muscle cramps or atrophy, diminished muscle stretch reflexes, paresis, fasciculations, and sensory loss [18]. The conventional belief is that occupation-induced mercury poisoning is the most common [19-21]. There are only a few domestic and overseas reports related to mercury poisoning caused by TCMs [12]. In this study, EMG showed that most nerve damage in patients was caused by CFRs, likely because occupational disease patients tend to be admitted to occupational disease hospitals. Mercury has a strong affinity for renal tissue which can lead to NS [15, 22-24]. Mercury-induced MN results from long-term use of mercury-containing skin-lightening cosmetics or from occupational contact with mercury [25-27]. Minimalchange glomerular lesions were detected in women in Kenya, who used mercury-containing skin-lightening creams [28], and four cases of MCN were described following the use of mercury-containing skin-lightening cream for 2-6 months [29]. Our study further supported the belief that $\mathrm{MN}$ and $\mathrm{MCN}$ occur following the use of mercury-containing skin-lightening creams. However, MN was also observed following the inappropriate use of CFRs [11]. The results of this study are consistent with those of most international mercury poisoning cases and reports [30] that used small samples. In addition, it contributes to the treatment and prognosis of mercury poisoning induced by mercury-containing CFRs.

As previously mentioned [31, 32], patients with mercury poisoning are often misdiagnosed in China as having digestive system diseases (acute abdomen and acute gastroenteritis), nervous system diseases (neurasthenia and vegetative nerve functional disturbance), and diseases of the urinary system (acute nephritis and nephritic syndrome). The reasons for the top two misdiagnosed diseases are incorrect history taking by doctors and a shortage of relevant knowledge about mercury poisoning. In China, mercury poisoning can only be definitively diagnosed and treatments provided at prevention and treatment centers for occupational diseases, such as the Centers for Disease Control [12, 32]. Prior to the establishment of poison treatment centers, mercury poisoning cases were mainly treated at the neurology, nephrology, and gastroenterology departments of hospitals, with most patients receiving symptomatic and not etiological treatment [33]. Moreover, although overseas researchers report some longterm follow-up prognoses for nephritic syndrome and peripheral nerve injury caused by mercury poisoning, domestic researchers do not report relevant aspects. Here, the follow-up results showed that the average recovery periods of nerve injury and nephritic syndrome caused by mercury poisoning were 38.5 and 22.67 months after dispelling mercury, respectively. Although there are specific therapeutic drugs and a sound prognosis for mercury poisoning, the state of the illness is prolonged for most patients because of the lack of education in mercury poisoning and a shortage of national poison testing centers, most of which are only used for occupational disease groups. Public awareness of the main causes of mercury poisoning, including the use of cosmetic products and CFRs and occupational exposure, must be increased to relieve the heavy burden of mercury poisoning on both rural Asian communities and their healthcare systems.

This study has several limitations. First, there is a lack of multicenter studies, and there are only a few poisoning treatment centers in China. Although our center is the largest poisoning treatment center, it mainly receives patients from North, Central, and East China, while receiving only few patients from South and West China. Second, owing to the sparse distribution of domestic mercury poisoning centers, low incomes, and high mobility of patients, the second follow-up was only conducted over the telephone, with some proportion lost to follow-up. Third, to comply with China's national requirements, we adopted the GBZ-2007 National Mercury Poisoning Diagnostic Standards, which have not been updated for a long time and differed from international standards. Fourth, patients with NS caused by mercury poisoning did not receive renal biopsy and could only be evaluated in terms of clinical cure.

\section{Conclusions}

In this article, we report the epidemiology, treatment, and prognosis of patients with mercury poisoning at a hospital in China. Our study found that (1) poisoning in China mainly occurred through occupational exposure and the use of cosmetics and CFRs, as previously reported; (2) mercury poisoning due to occupational exposure was more common in males in the 20-50 year-old age group, while female patients aged 20-50 years were more likely to experience cosmetics-related poisoning. Mercury poisoning due to inappropriate use of CFRs was observed at all ages, regardless of the sex; (3) patients with mercury poisoning caused by the inappropriate use of CFRs were more likely to have peripheral neurogenic damage; NS caused by mercury poisoning was mostly of the $\mathrm{MN}$ and $\mathrm{MCN}$ types following the use of mercury-containing skin-lightening creams and of the $\mathrm{MN}$ type following the inappropriate use of CFRs; (4) most severe complications of mercury poisoning (NS and peripheral nerve injury) can be alleviated by sodium DMPS treatment. 


\section{Abbreviations}

CFRs: Chinese folk remedies; DMPS: Sodium 2,3-dimercapto-1propanesulfonate; EMG: Electromyography; FSGS: Focal segmental glomerulosclerosis; HUM: High urine mercury; IQR: Interquartile range; MCN: Minimal-change nephropathy; MN: Membranous nephropathy; MSPG N: Mesangial proliferative glomerulonephritis; NS: Nephrotic syndrome; STROBE: Strengthening the Reporting of Observational studies in Epidemiology; TCMs: Traditional Chinese medicines; UMC: Urinary mercury/ creatinine

\section{Acknowledgements}

We would like to thank ZCC and LJW following up the patients.

\section{Authors' contributions}

Study design: LH and QZW. Data collection: SYW, PXB. Data analysis: SYW, PXB. Figures: LJH, ZJX. Manuscript writing: LH, QZW. Manuscript proofing: LJH, ZJX. All authors read and approved the manuscript.

\section{Funding}

This research did not receive any specific grant from funding agencies in the public, commercial, or not-for-profit sectors.

\section{Availability of data and materials}

The datasets during and/or analysed during the current study available from the corresponding author on reasonable request.

\section{Declarations}

\section{Ethics approval and consent to participate}

All human participants signed a written informed consent. Consent for participation in the study was obtained where participants are children (under 16 years old) from their parent or guardian. Ethics Committee of scientific research review of 307th Hospital of PLA (KY-2019-3-11).

\section{Consent for publication:}

Not applicable.

\section{Conflict of interest}

The authors declare no conflicts of interest.

\section{Author details}

'Department of Chemical Poisoning Treatment, Department of Hematology, Fifth Medical Center of Chinese PLA General Hospital, No. 8 Dong da Street, Fengtai District, 100071 Beijing, China. ${ }^{2}$ Pulmonary and Critical Care Medicine, Beijing Tiantan Hospital, Capital Medical University, 100050 Beijing, China.

Received: 29 August 2020 Accepted: 20 April 2021

Published online: 03 May 2021

\section{References}

1. Berglund $M$, Lind B, Bjornberg KA, Palm B, Einarsson O, Vahter M. Interindividual variations of human mercury exposure biomarkers: a crosssectional assessment. Environ Health. 2005;4:20.

2. He L, Liu F, Zhao J, Liu Q, Cui L, Yu YL, Fan Y, Li B, Li YF. Temporal trends of urinary mercury in Chinese people from 1970s to 2010s: a review. Ecotoxicol Environ Saf. 2021:208:111460.

3. Li Ping CM, Wang Bo. 中国居民甲基录暴露的来源和健康风险 [Sources and health risks of methylmercury exposure in Chinese residents]. Bull Mineralogy Petrology Geochem. 2019;38(4):725-728.

4. Weldon MM, Smolinski MS, Maroufi A, Hasty BW, Gilliss DL, Boulanger LL, Balluz LS, Dutton RJ. Mercury poisoning associated with a Mexican beauty cream. West J Med. 2000;173(1):15-8 discussion 19.

5. Calabrese EJ, lavicoli I, Calabrese V, Cory-Slechta DA, Giordano J. Elemental mercury neurotoxicity and clinical recovery of function: a review of findings, and implications for occupational health. Environ Res. 2018;163:134-48.

6. Li SJ, Zhang SH, Chen HP, Zeng CH, Zheng CX, Li LS, Liu ZH. Mercuryinduced membranous nephropathy: clinical and pathological features. Clin J Am Soc Nephrol. 2010;5(3):439-44.
7. Letz R, Gerr F, Cragle D, Green RC, Watkins J, Fidler AT. Residual neurologic deficits 30 years after occupational exposure to elemental mercury. Neurotoxicology. 2000;21(4):459-74

8. Chan TY. Inorganic mercury poisoning associated with skin-lightening cosmetic products. Clin Toxicol (Phila). 2011;49(10):886-91.

9. Ho YB, Abdullah NH, Hamsan H, Tan ESS. Mercury contamination in facial skin lightening creams and its health risks to user. Regul Toxicol Pharmacol. 2017;88:72-6

10. Zhou Bei ZC LX. 含录外用中药新药研发的思考 [Thinking of research and development on new traditional Chinese medicine drugs containing mercury for external use]. Chin J Clin Pharmacol. 2017;33(18):1847-1852.

11. Lu Y, Yang D, Song X, Wang S, Song M, Hang T. Bioaccessibility and health risk assessment of mercury in cinnabar containing traditional Chinese medicines. J Trace Elem Med Biol. 2017:44:17-25.

12. Mo T, Sun S, Wang Y, Luo D, Peng B, Xia Y. Mercury poisoning caused by Chinese folk prescription (CFP): a case report and analysis of both CFP and quackery. Med (Baltim). 2016;95(44):e5162

13. Wu ML, Deng JF, Lin KP, Tsai WJ. Lead, mercury, and arsenic poisoning due to topical use of traditional Chinese medicines. Am J Med. 2013;126(5):451-4.

14. Posadzki P, Watson L, Ernst E. Contamination and adulteration of herbal medicinal products (HMPs): an overview of systematic reviews. Eur J Clin Pharmacol. 2013;69(3):295-307.

15. Zhang L, Liu F, Peng Y, Sun L, Chen C. Nephrotic syndrome of minimal change disease following exposure to mercury-containing skin-lightening cream. Ann Saudi Med. 2014:34(3):257-61.

16. Wang $Y$, Fan LP, Song J, Cai YP, Jinang TT, Wang YG, Kong XW, Wu JR. Retrospective analysis and discussion on 74 cases of adverse reactions of traditional Chinese medicine injection. Zhongguo Zhong Yao Za Zhi. 2018; 43(21):4347-51.

17. Clarkson TW, Magos L, Myers GJ. The toxicology of mercury-current exposures and clinical manifestations. N Engl J Med. 2003;349(18): 1731-7.

18. Levine SP, Cavender GD, Langolf GD, Albers JW. Elemental mercury exposure: peripheral neurotoxicity. Br J Ind Med. 1982;39(2):136-9.

19. Nerudova J, Cabelkova Z, Frantik E, Lukas E, Urban P, Blaha K, Pelclova D, Lebedova J, Cikrt M. Mobilization of mercury by DMPS in occupationally exposed workers and in model experiments on rats: evaluation of body burden. Int J Occup Med Environ Health. 2000;13(2):131-46.

20. Miller JM, Chaffin DB, Smith RG. Subclinical psychomotor and neuromuscular changes in workers exposed to inorganic mercury. Am Ind Hyg Assoc J. 1975;36(10):725-33.

21. Kishi $R$, Doi $R$, Fukuchi $Y$, Satoh $H$, Satoh $T$, Ono A, Moriwaka F, Tashiro K, Takahata N, Sasatani H, et al. Residual neurobehavioural effects associated with chronic exposure to mercury vapour. Occup Environ Med. 1994:51(1):35-41.

22. Dhanapriya J, Gopalakrishnan N, Arun V, Dineshkumar T, Sakthirajan R, Balasubramaniyan T, Haris M. Acute kidney injury and disseminated intravascular coagulation due to mercuric chloride poisoning. Indian J Nephrol. 2016:26(3):206-8

23. Wagrowska-Danilewicz M, Danilewicz M, Zbrog Z. Mercury-induced nephrotic syndrome: a case report and review of the literature. Pol J Pathol. 2014;65(4):322-6.

24. Jiang YX, Xue N, Li Z, Yan YJ. A misdiagnosis case of kidney damage caused by mercury poisoning. Zhonghua Lao Dong Wei Sheng Zhi Ye Bing Za Zhi. 2020;38(7):544-5.

25. Aymaz S, Gross O, Krakamp B, Ortmann M, Dienes HP, Weber M. Membranous nephropathy from exposure to mercury in the fluorescenttube-recycling industry. Nephrol Dial Transplant. 2001;16(11):2253-5.

26. Oliveira DB, Foster G, Savill J, Syme PD, Taylor A. Membranous nephropathy caused by mercury-containing skin lightening cream. Postgrad Med J. 1987; 63(738):303-4

27. Chakera A, Lasserson D, Beck LH Jr, Roberts IS, Winearls CG. Membranous nephropathy after use of UK-manufactured skin creams containing mercury. QJM. 2011:104(10):893-6.

28. Barr RD, Rees PH, Cordy PE, Kungu A, Woodger BA, Cameron HM. Nephrotic syndrome in adult Africans in Nairobi. Br Med J. 1972;2(5806): $131-4$.

29. Tang HL, Mak YF, Chu KH, Lee W, Fung SK, Chan TY, Tong KL. Minimal change disease caused by exposure to mercury-containing skin lightening cream: a report of 4 cases. Clin Nephrol. 2013:79(4):326-9. 
30. Doshi M, Annigeri RA, Kowdle PC, Subba Rao B, Varman M. Membranous nephropathy due to chronic mercury poisoning from traditional Indian medicines: report of five cases. Clin Kidney J. 2019; 12(2):239-44.

31. DJQ Z. 录中毒致周围神经病变误诊报告并文献复习 [Misdiagnosis and literature review of mercury-induced peripheral neuropathy]. Clin Misdiagnosis Mistherapy. 2016;29(8):45-47.

32. Liping Z. 86 例录中毒误诊分析 [Misdiagnosis analysis of 86 cases of mercury poisoning]. J Appl Prev Med. 2010;16(2):105-107.

33. Zhang Peng QZ. 金属录中毒脏器功能损伤研究进展 [Research progress on organ function damage of metal mercury poisoning]. J Clin Emerg. 2016; 17(11):819-822.

\section{Publisher's Note}

Springer Nature remains neutral with regard to jurisdictional claims in published maps and institutional affiliations.

- fast, convenient online submission

- thorough peer review by experienced researchers in your field

- rapid publication on acceptance

- support for research data, including large and complex data types

- gold Open Access which fosters wider collaboration and increased citations

- maximum visibility for your research: over $100 \mathrm{M}$ website views per year

At $\mathrm{BMC}$, research is always in progress. 